\title{
La vivencia del tiempo en la psicología normal y en la patológica, II.
}

\section{Time experience in normal and pathological psychology.}

RESUMEN: Se describe la vivencia del tiempo en la psicología normal y en la patológica y se realizan aportaciones acerca de trastornos de la vivencia del tiempo en adicciones y neurosis (obsesiones y fobias).

PALABRAS CLAVE: Vivencia del tiempo. Psicopatología. Adicciones. Neurosis.
ABSTRACT: Time experience in normal and pathological psychology is described, and some contributions about the sense of time in addictive disorders and neurosis (obsessions and phobias).

KEY WORDS: Time experience. Psychopathology. Addictions. Neurosis.

\section{Introducción.}

La noción de temporalidad afecta a toda la existencia humana resultando su vivencia y la expresión conductual de ésta un marcador de organización del Yo tanto a lo largo del desarrollo individual como en el terreno más específico de los trastornos mentales.

Esta es una hipótesis que puede postularse a partir de la fenomenología, el psicoanálisis y la observación clínica de la psicopatología y que puede marcar algunas líneas de investigación productivas con aplicación en nuestro quehacer terapéutico.

Conceptos tales como impulsividad, pasividad o tolerancia a la frustración están determinados por un aspecto temporal el cual marca la adecuación o no de una conducta. Adecuación y organización nos llevan reiteradamente a contemplar ese aspecto de secuencia y ritmo en un repertorio de actuaciones que juzgaremos acordes o no a la realidad en un momento dado.

El estudio del tiempo, de gran actualidad en otros campos de la ciencia, tiene gran relevancia en la experiencia subjetiva del enfermo mental y nos corresponde reconocer en éste la manera peculiar en que lo vive. La manera en que se presenta en consulta, como se produce en la misma, la generación de la alianza terapéutica y el porvenir de ésta van a verse muy influidos por nuestra capacidad para percibir y adecuarnos al sentir de los tiempos peculiares de cada paciente, imprimiendo cada uno de ellos un tiempo especial y distintivo, esencial para la empatía imprescindible en el acto terapéutico. 
El hecho de que tiempo y ritmo es un elemento determinante en psico(pato) logía nos viene ejemplificado en el poder evocador de la música, capaz de alcanzar funcionamientos, estratos o núcleos, como queramos conceptuar, no accesibles a otras modalidades perceptivas; en definitiva, no es posible percibir nada, interno o externo, ajeno a un ritmo, anclado de la forma más primaria en lo biológico.

\section{Material y Método}

En cuanto a la metodología se reflejan aportaciones teóricas de diversos autores, introduciendo después hipótesis acerca de los trastornos en la vivencia del tiempo en psicopatología, particularmente en adicciones, resumiendo el trabajo de 1996 (1) y algunas nuevas aportaciones acerca de las neurosis, en las que la alteración del sentido del tiempo tiene especial significación.

Abordaré en primer lugar las aportaciones teóricas sobre el tema, tomando de los marcos teóricos de la fenomenología el acento en la vivencia subjetiva y del psicoanálisis el modelo de aparato psíquico establecido por Freud, si bien centrándonos en la experiencia "aquí y ahora" de la conciencia más que en sus raíces genéticas.

No se tratará en el presente trabajo la vinculación del sentido de temporalidad con los procesos de memoria ya que, como se acaba de indicar, es el sentir subjetivo del tiempo "ahora" el foco de este trabajo.

Se establecen hipótesis en base a la observación directa de los pacientes en la consulta clínica habitual en Centro de Salud Mental, así como a los informes subjetivos de éstos, hipótesis que en todo caso, requerirán validación en trabajos posteriores.

\section{La temporalidad en Psicoanálisis}

Es obligada una primera referencia al postulado psicoanalítico de la atemporalidad del inconsciente, según el cual, para Freud, los procesos que ocurren en éste "se hallan fuera del tiempo, esto es, no aparecen ordenados cronológicamente, no sufren modificación ninguna por el transcurso del tiempo y carecen de toda relación con él, la relación temporal se halla ligada a la labor del sistema consciente". El ser humano adquiere la idea del tiempo por proyección a partir de un tiempo interno subjetivo que se va desarrollando en base a una alternancia de 
ORIGINALES BREVES

investiduras entre el inconsciente y el sistema percepción-conciencia; el ritmo de esas investiduras y desinvestiduras es lo que produce, según Freud la noción del tiempo (2).

Con posterioridad otros autores destacan la función materna como primer organizador del tiempo, así Sami-Ali (3) señala como esbozo de toda temporalidad los cuidados maternos en una secuencia de cargas y descargas, tensiones y aflojamientos, relacionando de modo inseparable la aparición de la vivencia del tiempo a la relación con el otro. Otros autores tales como A. Fontana (4) y M. Klein también vinculan la adquisición de la temporalidad con la maduración afectiva en el seno de la relación de objeto, muy en especial con el advenimiento de la llamada, según Klein, "posición depresiva” (5).

Autores franceses han vinculado más específicamente la función preconsciente con la constitución de la temporalidad y han aportado conceptos como el "recuerdo pantalla" y el "après coup" como formas distintivas del neurótico de vivenciar el tiempo (6).

Desde otros puntos de vista se vincula el concepto del tiempo con la maduración del self y con la capacidad adaptativa del Yo como señalan Arlow (7) y Master (8) respectivamente; considerando la vivencia del tiempo anclada en los ritmos fisiológicos; el tiempo representa la necesidad real, por lo que tiempo y realidad se van conectando e integrando progresivamente en un Yo en maduración.

Desde la perspectiva de las pulsiones Rosenberg (9) considera a la pulsión de vida como artífice de la historicidad, la causalidad psíquica y la temporalidad, conteniendo y conservando cada estado psíquico en el que le sucede y a su contraria como causante de lentificación y hasta detención del tiempo, atribuyendo a la intrincación pulsional la construcción del tiempo y de la historia.

\section{Percepción del Tiempo y Psicopatologia}

Dentro de una acepción general del término estrés convenimos que éste domina en la actualidad como una psicopatología de nuestra vida cotidiana en la que se vuelve angustiosa la lucha contra el tiempo. Asimismo la llegada de nuevas tecnologías y la sociedad de la información y la comunicación está dimensionando el tiempo humano de una forma nueva generando nuevas posibilidades y en ocasiones distorsiones perceptivas que acaban apareciendo como síntomas.

El concepto de estrés vinculado en nuestra práctica a los trastornos de adaptación conlleva una clara dimensión temporal en el sentido de exceso de presión en un espacio de tiempo en el cual no es posible el trabajo de elaboración mental. 
Algo parecido, llevado a una situación extrema, es lo que sucede en el trauma psíquico en el cual la mente es incapaz de tolerar una determinada sobreexcitación que ocurre en un corto período de tiempo; otras veces el suceso es traumático por su reiteración, manteniéndose el suceso estresante en una secuencia repetitiva.

También se ha descrito, dentro de la experiencia humana normal, léase Proust, momentos de exaltación con borramiento de la temporalidad, que describe Bollnow (10) como vivencias que cambian radicalmente la vida de quien las experimenta, el cual sufre una verdadera reorganización o transformación, vivencias de este tipo se producen en el éxtasis y en sujetos que han sufrido grave riesgo de muerte.

Dentro de la psicopatología, en la euforia maníaca y en la intoxicación por sustancias estimulantes el tiempo se precipita en la vivencia de aceleración del tiempo (11), en el polo opuesto en la depresión grave, en la esquizofrenia y en otras intoxicaciones se vive el tiempo lentificado e incluso detenido, en estos últimos puede llegarse a perder completamente el sentido de realidad del tiempo, como también ocurre en la despersonalización y la desrealización.(12). Las alteraciones del tiempo que se producen en el jamais vu o en el déjà vu vienen dadas por una modificación del sentido de familiaridad que inviste los objetos (13).

En la melancolía investigaciones experimentales han confirmado la subestimación del tiempo prospectivo por parte de los enfermos en relación a controles normales, correlacionándose ésta con la severidad de la depresión (14).Se ha comprobado experimentalmente que enfermos melancólicos subestiman el tiempo prospectivo en relación a controles normales.

Se ha verificado una sobreestimación del paso del tiempo en la llamada personalidad tipo A, que puede explicar su elevado nivel de actividad (15). En la vida cotidiana también se puede percibir aceleración del paso del tiempo en la hiperactividad, así como en el transcurso de la vida, al avanzar la edad, la vivencia del tiempo es cada vez más notoria y tiende a percibirse también acelerada.

Si en la ansiedad se percibe una sensación de presión del tiempo, en otras neurosis y trastornos borderline se produce una pérdida episódica de la experiencia del tiempo (16), con la consiguiente alteración en la identidad histórica del sujeto. En definitiva, siguiendo a Boschan (17), la aceptación de la temporalidad pone límites al narcisismo y la omnipotencia, situación que solo se supera mediante las relaciones de objeto. Cuanto mayor es la alteración en la relación de objeto, mayor es la alteración en la temporalidad, difiriendo la acción hasta el infinito como en el caso del obsesivo para mantener la distancia con el objeto (18), o mediante la evitación como el fóbico, patologías a las que dedicaré una atención especial más adelante. 
ORIGINALES BREVES

Resultados Observacionales.

Temporalidad, Adicciones y Trastornos Neuróticos.

Ya hemos descrito en el trabajo citado a las dependencias (incluyendo drogodependencias, juego patológico y trastornos alimentarios) como verdaderas "enfermedades del tiempo", caracterizadas por:

-Un déficit en la función del Yo que adecua tiempo interno y tiempo externo, real o convencional, instaurándose el hábito o el tóxico como una "prótesis" del Yo.

-Una "suspensión temporal" durante el consumo o ejercicio del hábito en la cual el sujeto se vivencia fuera del tiempo convencional, el cual entonces se fracciona o divide, en una secuencia tolerable, llegando en los casos más graves a una práctica desaparición del tiempo convencional, entrando el paciente en una serie continua de consumo-abstinencia-consumo.

-La carencia de la sustancia tóxica o del ejercicio del hábito crea una vivencia angustiosa de la temporalidad, la cual se percibe como intolerable, dando cuenta de una desorganización del Yo en su capacidad de adecuación del tiempo interno al tiempo real o convencional.

La escasa tolerancia a la frustración del adicto es síntoma de este Yo desorganizado en su capacidad de regulación de la temporalidad.

Tomando el caso de la patología neurótica, obsesiones y fobias, podemos encontrar también una vivencia patológica del tiempo que podría definirse como una baja "tolerancia al apremio". Conocemos el estilo defensivo del neurótico y hasta que punto puede verse comprometido, sobreviniendo la crisis de angustia si se le apremia en el "ahora".

Este hecho es particularmente evidente en la fobia, dado que el paciente es muchas veces capaz de llevar a cabo la conducta temida, siempre y cuando se le tolere elegir el momento adecuado, a su propio tiempo, y sin apremio.

Observaciones clínicas habituales de pacientes fóbicos cuando deben aguardar turno en una fila, esperar antes de llevar a cabo una presentación o de entrar en consulta hacen ver esta distorsión de la temporalidad, en la cual la inminencia o apremio del "ahora" termina de comprometer su sistema defensivo. Vive, pues, el fóbico, una temporalidad angustiosa entre la anticipación antes de la conducta temida y el apremio ante la inminencia de la misma.

En el paciente obsesivo es notoria la necesidad de control temporal, el ritual debe ser efectuado, quedando así otras conductas diferidas y el apremio por parte del ambiente para llevar a cabo conductas más adecuadas puede ser detonante de la crisis de angustia.

Vemos así que la exacerbación de los síntomas en fobias y obsesiones va paralela a una desorganización del Yo en cuanto a su capacidad de adecuación de la temporalidad. 
Podemos entonces complementar lo anteriormente expuesto para las adicciones con otras características más específicas para la patología neurótica, como son:

-En las neurosis fóbicas y obsesivas se suelen presentar, acompañando a su clínica principal, distorsiones severas en la vivencia del tiempo, con notable desajuste entre tiempo interno y tiempo real.

-En estas patologías se produce una baja "tolerancia al apremio" cuando el paciente se ve exigido a una determinada conducta ya afectada por un sistema defensivo comprometido.

-Se observa con frecuencia que tales conductas temidas pueden darse con más facilidad si se permite el desenvolvimiento de éstas dentro de una temporalidad que es propia y necesaria para cada paciente.

-En este sentido, la tarea terapéutica consiste en la adecuación progresiva entre tiempo interno y tiempo real, regulando y aumentando la tolerancia al apremio, manteniendo quizá que todo paciente ó todo psiquismo cuenta con un primordial "narcisismo del tiempo".

Tanto en las patologías neuróticas como en las adicciones, que aquí abordamos en su dimensión de la vivencia de la temporalidad, un aspecto importante del trabajo terapéutico con tales pacientes implica una restauración progresiva de la función del Yo relativa a la temporalidad, de manera que prescindir o reducir el tóxico, el hábito o la defensa patológica representa una verdadera reorganización del Yo en su dimensión de adecuación temporal.

\section{Conclusiones}

Partiendo del hecho reconocido de las anomalías en la vivencia del tiempo en la psicopatología se han revisado los orígenes de la percepción y organización de la temporalidad en el desarrollo psíquico normal, así como los trastornos de la misma en diversas patologías mentales.

Se han aportado observaciones y teorizaciones acerca de alteraciones específicas de la vivencia temporal en patologías adictivas y neuróticas, dándose en las primeras una suspensión temporal y en las segundas una intolerancia al apremio, manifestándose en ambas un déficit en la función adaptativa del Yo en su capacidad de adecuación entre tiempo interno y tiempo real o convencional.

Estas aportaciones pueden enriquecer la valoración psicopatológica de nuestros pacientes, favoreciendo una mayor comprensión de los mismos de cara a una alianza y trabajo terapéutico más productivo. 


\section{BIBLIOGRAFÍA:}

(1) García Castro,E., Salado, J., "La vivencia del tiempo en la psicología normal y en la patológica”. Revista de la Asociación Española de Neuropsiquiatría, no 60 oct/dic 1996, Vol. XVI, pp. 29-35.

(2) Freud, S. "Los inconsciente", Obras Completas, Madrid, Biblioteca Nueva, 1981.

(3) Sami-Ali., El cuerpo, el espacio y el tiempo, Buenos Aires, Amorortu, 1993.

(4) Fontana, A.E., "Técnicas de control frente a la vivencia del transcurso del tiempo (Identificación Proyectiva, Fragmentación e Hipocondría)", Revista de Psicoanálisis, 1960, nº 1, Vol. 17.

(5) Klein M., Obras Completas, Barcelona, Paidós, 1975.

(6) Rouart, J. "Prèconscient et temps, Rev. Franç. Psychanal, 1992,4.

(7) ArLow, J., « Disturbances of the Sense of Time with Special Reference to Experience of Timelessness", Psychoanalytic Quarterly, 1984, LIII.

(8) Masler, E.,"The Subjective Percepcion of Two Aspects of Time Duration and Timelessness", Int.J. Psycho-Anal, 1973, 54, p. 425.

(9) Rosemberg B., "Tiempo e historia. Su relación con el trabajo psíquico y las pulsiones". Revista de Psicoanálisis de la Asoc. Psic. de Madrid, 2002, nº 37.

(10) Bollnow en Rof Carballo, J., Cerebro interno y mundo emocional, Asociación Gallega de Psiquiatría, 2001.

(11) Scharfetter, Ch., Introducción a la Psicopatología General, Morata, Madrid, 1988.

(12) Sims, A.. Symptoms in the Mind: an Introduction to Descriptive Psychopathology, Londres, Baillière Tindall, 1988

(13) García Castro, E. Lucas Carbonero, G. "Acerca de una alteración de la percepción en el duelo y otras patologías” Psiquiatría Pública, Vol 10, nº 4, 1988.

(14) Kuns, H. y otros., "Time Estimation and the Experience of Time in Endogenous Depression /Melancholia): An Experimental Investigation”, Psychopathology,1991, 24, pp. 7-11.

(15) VÁzquez, C., "Psicopatología de la memoria y vivencia del tiempo", en Luque, R. y Villagrán J.M., Psicopatología Descriptiva:Nuevas Tendencias, Madrid, Trotta, 2000.

(16) Shoda, H., "Splitting Phenomena from a Viewpoint of Experiencing Time: Spectrum from Multiple Personality anh Hysteria to Borderline Personality Disorder", Psychopathology, 1993, 26, pp. 240-254.

(17) Boschan, P., "Temporality and Narcissism", Int. Rev. Psycho-Anal, 1990, 17, p.337.

(18) Castellano-Maury, E., "Actualidad, temporalidad", Revista de Psicoanalisis de la Asoc. Psic. de Madrid, 2002, no 37, pp.41-54.

* EMILIA GARCÍACASTRO: Psiquiatra. Centro de Salud Mental ILa Magdalena, C/ Valdés Salas s/n.33402. Avilés, Asturias.

Correspondencia: Correo electrónico: emilia.garciac@sespa.princast.es

** Recibido: 3/04/2009 